jirtes Zinn, von deon sich ein Theil leicht und rasch auflöst. Diese Lõsung, welche das Zinn als Chlorür wieder enthält, wird zur Fällung der Harnsãurelösung in Salpetersâure wie das reine Zinnchlorür verwendet, so dafs also dieses immer wieder dient.

Diese Methode, welche ich seit sechs Jahren in meinen Vorlesungen als die beste empfohlen habe, liefert von einer gegehenen Menge reiner Harnsãure sehr nahe das theoretisch berechnete Quantum Alloxan.

\title{
Ueber die Einwirkung der Salpetersäure auf Pikraminsäure;
} von J. Stenhouse *).

Die widersprechenden Angaben, welche bezüglich der Einwirkung der Salpetersãure auf Pikraminsãure veröffentlicht worden sind, veranlafsten mich, diese Einwirkung zu untersuchen. Girard und $\mathrm{P} \mathbf{u} \mathrm{g} h$ **) gaben an, dafs die Pikraminsãure bei Behandlung mit starker Salpetersäure zu Pikrinsãure umgewandelt werde. Wöhler und Carey Lea ***) gaben hingegen an, dafs die Pikraminsãure nicht durch die Einwirkung von Salpetersäure zu Pikrinsäure umgewandelt werde.

*) Aus dem Journal of the Chemical Society, new series, VI, 150 mitgetheilt.

**) Girard, diese Annalen IXXXVIII, 282; Pug h daselbst XCVI, 83.

***) Wühler, Pogg. Ann. XIII, 488; Carey Loa, Silliman's Amer. Journ. [2] XXVI, 279.

Anual. d. Chear. u. Pharm. CXLVH. Bd. y. Heft. 
Drei Gewichtstheile siedender Salpetersãure von 1,45 spec. Gew. wurden auf 1 Th. Pikraminsäure gegossen, welche sich rasch löste, und nach wenigen Minuten trat eine heftige Reaction ein, bei welcher salpetrige Dämpfe mit fast explosionsartiger Heftigkeit entwickelt wurden. Als die Einwirkung etwas nachgelassen hatte, wurde das Gemische erwärmt, und nachdem die Digestion noch etwa 10 Minuten angedauert hatte, liếs man die Flüssigkeit abkühlen. Nach einigem Stehen schied dieselbe eine krystallinische Substanz in so grofser Menge aus, dafs sie dadurch zu einer halbfesten Masse erstarrte. Von den Krystallen liefs man die saure Flüssigkeit auf einem Trichter abtropfen, in welchem ein Pfropfen von Schiefsbaumwolle steckte; dann wurden die Krystalle auf einem porösen Ziegelstein getrocknet und nach 2- bis 3 maligem Krystallisiren aus Weingeist analysirt. Die Resultate der Analyse entsprachen der Formel $\mathrm{C}_{6} \mathrm{H}_{2} \mathrm{~N}_{4} \mathrm{O}_{5}$ :

\begin{tabular}{|c|c|c|c|c|}
\hline \multicolumn{3}{|c|}{ berechnet } & \multicolumn{2}{|c|}{ gefunden } \\
\hline $\mathrm{C}_{6}$ & 72 & 34,28 & 34,22 & 34,36 \\
\hline $\mathbf{H}_{2}$ & 2 & 0,95 & 1,36 & 1,31 \\
\hline $\mathbf{N}_{6}$ & 56 & 26,67 & - & - \\
\hline $\mathrm{O}_{5}$ & 80 & 38,10 & - & 一 \\
\hline & 210 & 100,00 & & \\
\hline
\end{tabular}

Aus diesen analytischen Resultaten ersieht man, dafs die eben besprochene Irystallinische Verbindung der $\mathrm{Zu}$ sammensetzung nach mit Griefs' Diazodinitrophenol $\mathrm{C}_{6} \mathrm{H}_{2} \mathrm{~N}_{2}\left(\mathrm{NO}_{2}\right)_{2} \mathrm{O}$ *) identisch ist, welchem sie auch in ihren physikalischen Eigenschaften entspricht.

Die Flüssigkeit, aus welcher sich das Diazodinitrophenol abgeschieden hatte, gab stärker concentrirt Krystalle, welche

*) Griefs, diese Annalen CXIII, 205. 
nach der Reinigung durch wiederholtes Umkrystallisiren aus Wasser die Zusammensetzung und die Eigenschaften der Pikrinsăure zeigten. Die Resultate der Analyse derselben waren :

\begin{tabular}{ccr}
\multicolumn{3}{c}{ berechnet } \\
\hline $\mathrm{C}_{8}$ & 72 & 31,44 \\
$\mathrm{H}_{8}$ & 3 & 1,31 \\
$\mathrm{~N}_{8}$ & 42 & 18,34 \\
$\mathrm{O}_{7}$ & 112 & 48,91 \\
\cline { 2 - 3 } & 229 & $100,00$.
\end{tabular}

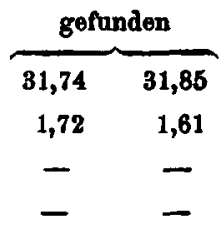

Auch das Silbersalz dieser Säure wurde dargestelltb durch Neutralisiren der Săure mit kohlensaurem Silber und Umkrystallisiren des Productes. Das Salz ergab 32,05 pC. Silber; nach der Formel $\mathrm{C}_{6} \mathrm{H}_{2} \mathrm{Ag}\left(\mathrm{NO}_{8}\right)_{8} \mathrm{O}$ berechnen sich $32,15 \mathrm{pC}$.

Bei den meisten der von mir angestellten Versuche bildete sich viel Diazodinitrophenol und verhältnifsmärsig wenig Pikrinsăure. In einem Falle jedoch ergab sich ganz das Entgegengesetzte; kaum irgend welche salpetrige Dămpfe wurden ausgestofsen und Pikrinsăure war das Hauptproduct. Bei der Einwirkung von Salpetersăure auf Pikraminsăure bilden sich also Diazodinitrophenol und Pikrinsäure in wechselnden Verhältnissen, welche wahrscheinlich auf der Temperatur und der Stärke der angewendeten Salpetersãure beruhen, woraus sich die widersprechenden Resultate früherer Beobachter erklären. 